\title{
Internal fixation using fully threaded cannulated compression screws for fresh femoral neck fractures in adults
}

\author{
Kai-xuan Yuan ${ }^{\dagger}$, Fan Yang ${ }^{\dagger}$, Kai Fu, Dao-yu Zhu, Chen-yi Jiang, Dong-xu Jin, Ze-hao Wang, Xiao-yuan Peng, \\ You-Shui Gao ${ }^{*+}$ and Peng-bo Luo ${ }^{*+}$ (D)
}

\begin{abstract}
Objectives: Internal fixation with multiple cannulated compression screws is an optional treatment for femoral neck fracture. Recently, fully threaded cannulated compression screws (FTCCS) have been introduced to fix fresh femoral neck fractures (FNF). The purpose of this study was to investigate the effectiveness of FTCCS.

Patients and methods: Patients with FNF fixed by multiple FTCCS from February 1st, 2014 to August 31 st, 2017 were included in this study. They were followed for at least 12 months postoperatively. Nonunion, osteonecrosis of the femoral head (ONFH), fixation failure, reoperation, and femoral neck shortening (FNS) were used to evaluate the outcomes. Risk factors including age, sex, fracture side, fracture displacement, fracture stability, fixation configuration, and screw numbers were analyzed.

Results: A total of 113 patients including 67 males and 46 females with an average age of $48.4 \pm 13.4$ years were included. The mean duration of follow-up was 27.1 months (range: 12-51 months). The incidence of nonunion, ONFH, fixation failure, and reoperation was $15.9 \%, 22.1 \%, 8.8 \%$, and $24.8 \%$, respectively. The rates of nonunion and reoperation were significantly higher in displaced fractures and unstable fractures. And patients with an unstable fracture had a higher risk of internal fixation failure. The median length of FNS was $2.9 \mathrm{~mm}$ (interquartile range: 0.9-6.5 mm, range: 0-17.5 mm). Age was a significant risk factor for FNS.

Conclusions: The screw fixation method with FTCCS provided encouraging clinical results which may be a rational choice for the treatment of fresh FNF. Displaced fractures and unstable fractures were attributed to the higher incidence of complications.

Trial registration: ChiCTR, ChiCTR1800017200. Registered 17 July 2018-Retrospectively registered, http: www.chictr.org. cn/showprojen.aspx?proj=29182.
\end{abstract}

Keywords: Femoral neck fracture, Fully threaded screws, Internal fixation, Complications

*Correspondence: gaoyoushui@sjtu.edu.cn; Luopb@hotmail.com ${ }^{\dagger}$ Kai-xuan Yuan and Fan Yang contributed equally to the work as cofirstauthor. You-Shui Gao and Peng-bo Luo contributed equally to the work as co-correspondence

Department of Orthopedics, Shanghai Jiaotong University Affiliated Sixth People's Hospital, No. 600 Yishan Road, Shanghai 200233, China

\begin{abstract}
Introduction
Femoral neck fractures (FNF) are a dangerous type of musculoskeletal injury and result in significant morbidity and mortality, accounting for $3.6 \%$ of all fractures and $53-56 \%$ of hip fractures [1]. The World Health Organization predicts that the incidence of FNF will increase more than threefold by 2050 [2]. Regardless of the degree of displacement, anatomic reduction and
\end{abstract} original author(s) and the source, provide a link to the Creative Commons licence, and indicate if changes were made. The images or other third party material in this article are included in the article's Creative Commons licence, unless indicated otherwise in a credit line to the material. If material is not included in the article's Creative Commons licence and your intended use is not permitted by statutory regulation or exceeds the permitted use, you will need to obtain permission directly from the copyright holder. To view a copy of this licence, visit http://creativecommons.org/licenses/by/4.0/. The Creative Commons Public Domain Dedication waiver (http://creativecommons.org/publicdomain/zero/1.0/) applies to the data made available in this article, unless otherwise stated in a credit line to the data. 
stable internal fixation are recommended for patients younger than 70 years with FNF $[3,4]$ except those who are seriously ill and present excessive surgical risk [5]. Numerous surgical techniques and implants have been developed and used for the treatment of FNF. However, there is no widespread consensus on the optimal fixation techniques and constructs to match the morphology of FNF [6].

For decades, internal fixation using multiple partially threaded cannulated compression screws (PTCCS) remains a standard method for FNF management $[7,8]$. These implants hasten to heal through dynamic fracture compression caused by axial loading during weight bearing. However, loss of fixation after closed reduction with three PTCCS is reported to be up to $39 \%$ within the first three postoperative months [9], and the subsequent complications including femoral neck shortening (FNS), nonunion, avascular necrosis, and malunion were believed to limit physical function [10].

Biomechanical study demonstrated that the use of screws with increased threads in the metaphysis and the femoral neck might prevent the occurrence of abnormal femoral neck configuration and nonunion of FNF [11]. The construct with a fully threaded positioning screw instead of a partially threaded positioning screw significantly improves the anterior-posterior stiffness and reduces the collapse of the fracture in artificial femurs [12]. Lately, the fully threaded cannulated compression screws (FTCCS) have been introduced to fix large bones in the upper and lower extremities. Compared with traditional PTCCS, the innovative design of the screws includes a patented taper, variable thread pitch, and fully threaded length to provide firm compression and holding power for fractures to minimize hardware loosening and breakage. A very recent study demonstrated that compared with using three traditional PTCCS alone, using fixation of a traditional PTCCS plus two FTCCS improved the clinical outcome [13]. Okcu et al. [14] examined three or four FTCCS with the closed reduction in 22 patients with FNF, and there was no difference of hip scores compared with those using PTCCS.

Nonetheless, to our knowledge, there has been a lack of literature regarding the use of multiple FTCCS alone in the management of FNF with a large sample size and a long follow-up period, to ensure a representative distribution of the population and to be considered representative of groups of patients to whom results will be generalized [14].

The purpose of this study was to investigate the effectiveness of FTCCS in patients with displaced and nondisplaced fresh FNF, mainly analyzing the occurrence of osteonecrosis of the femoral head (ONFH), nonunion, fixation failure, FNS, and reoperation.

\section{Patients and methods}

\section{Patients}

Adult patients admitted to our hospital to treat FNF with FTCCS (7.5 mm, Acumed, Hillsboro, Oregon) between February 1st, 2014 and August 31st, 2017 were included in this study. The time to surgery was $2-4$ days after injury. Patients with pathological fractures, associated ipsilateral lower limb fractures, severe spinal or craniocerebral trauma, psychiatric illness, and those younger than 18 years old or treated with other implants were excluded. This study was approved by the ethics committee of our hospital.

Surgeries were performed by experienced orthopedic surgeons under general anesthesia. Patients received closed reduction in supine position on a fracture traction table. Routine anterior posterior (AP) and lateral planes $\mathrm{X}$-ray were used to evaluate the reduction quality. If the satisfaction of the closed reduction was not gained, open reduction was performed. After successful reduction, the guide wires were inserted in a triangle or in an inverted triangle configuration. Then, the guide wires were measured, screw holes were drilled, and three $7.5 \mathrm{~mm}$ FTCCS were inserted. Sometimes one more horizontal screw was used according to the preference of the surgeons (Fig. 1).

Postoperatively, weight bearing was restricted for at least 12 weeks, but movement of the hip and muscle strength exercises on the bed were allowed. Afterward, weight bearing increased gradually.

$\mathrm{AP}$ and lateral X-rays of the hip joint were taken at 1.5, 3,6 , and 12 months postoperatively. Patients were also followed up by telephone to investigate their living conditions or reoperations/complications that were not shown in the radiographs.

All patients were followed up with a minimum duration of 12 months. All participants provided informed consent and they could withdraw any time during this study.

\section{Radiographic analysis}

Radiographic data (preoperative and postoperative planes) were collected. Radiographs were used to assess fracture classification, fixation configuration, screw number, fracture healing, and complications including nonunion, $\mathrm{ONFH}$, and internal fixation failure. Fracture classification included two aspects: Pauwels classification [15] and Garden classification [16]. Based on Pauwels classification, fractures were classified as stable (Pauwels type I and II) and unstable (Pauwels type III); according to Garden classification, fractures were distinguished into nondisplaced (Garden type I and II) and displaced (Garden type III and IV).

Nonunion was defined as a clear fracture line existing or displacement of the fracture on the radiographs at 12 months after surgery. ONFH was identified by 

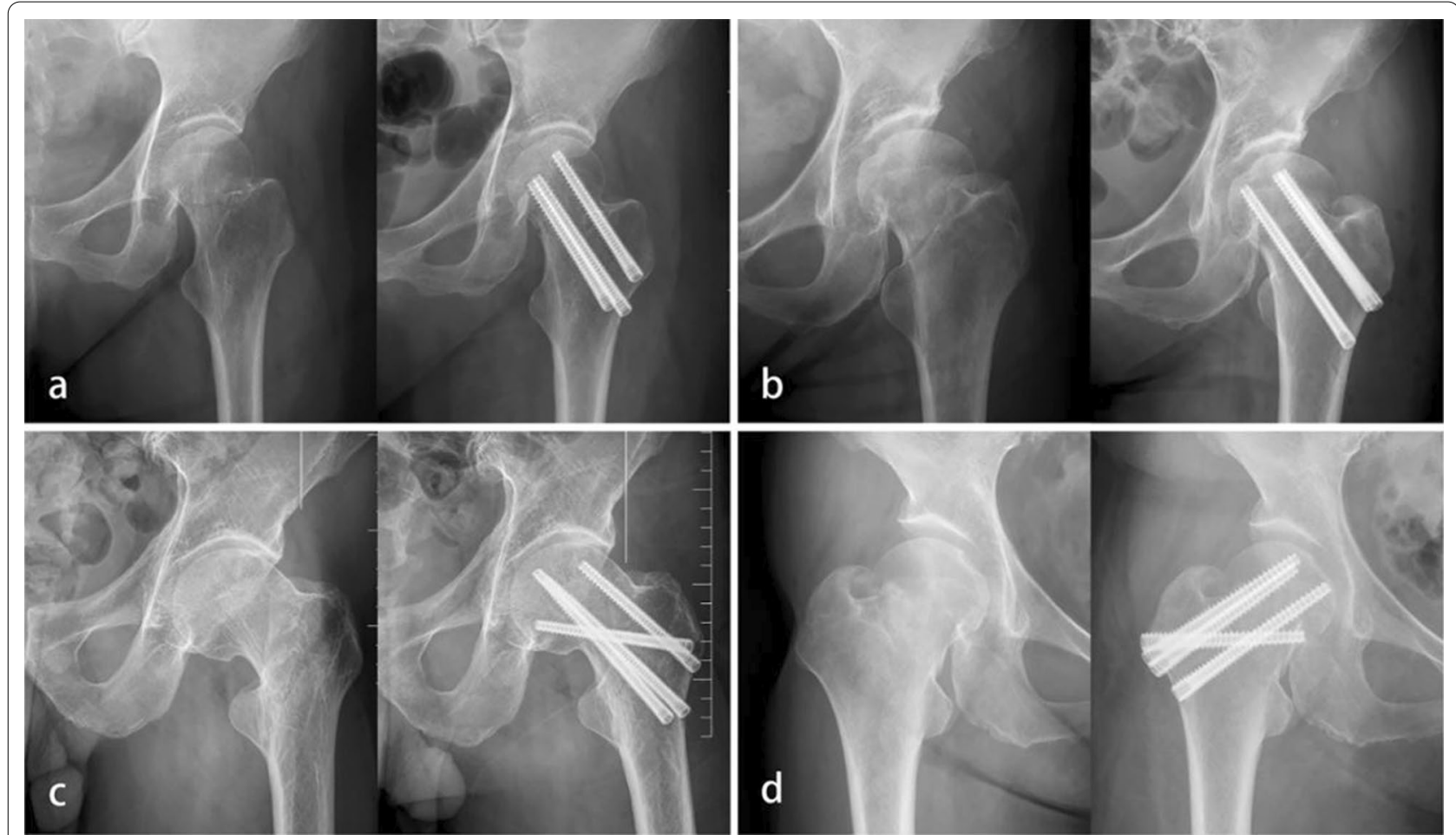

Fig. 1 Preoperative and postoperative anterior posterior radiographs of femoral neck fracture treated with fully threaded cannulated compression screws. a Fixed by three screws in a triangle configuration. $\mathbf{b}$ Fixed by three screws in an inverted triangle configuration. $\mathbf{c}$ Fixed by four screws in a triangle configuration. $\mathbf{d}$ Fixed by four screws in an inverted triangle configuration

radiographic signs of Ficat osteonecrosis stage II-IV on any radiograph after surgery [17]. Failure of internal fixation was defined as screws bending, dislocation, or breakage.

The FNS was measured by the method described by Yin et al. [18]. In brief, on the anteroposterior radiographs, a line was made through the center of femoral head in the long axis of the femoral neck, and the distance between the tip of the femoral head and the intertrochanteric line was measured on both sides. The length of FNS is the length on the contralateral side minus the length on the fracture side (Fig. 2).

\section{Statistical analysis}

Categorical variables were presented as numbers and percentages (\%), and continuous variables were presented as the mean and standard deviation. Differences between groups were compared using the chi-square test or Fisher's exact test and $t$-test. Statistical analysis was performed using IBM SPSS Statistics (version 24.0; Chicago, USA). A $p$ value of $\leq 0.05$ (2-sided test) was considered as statistically significant.

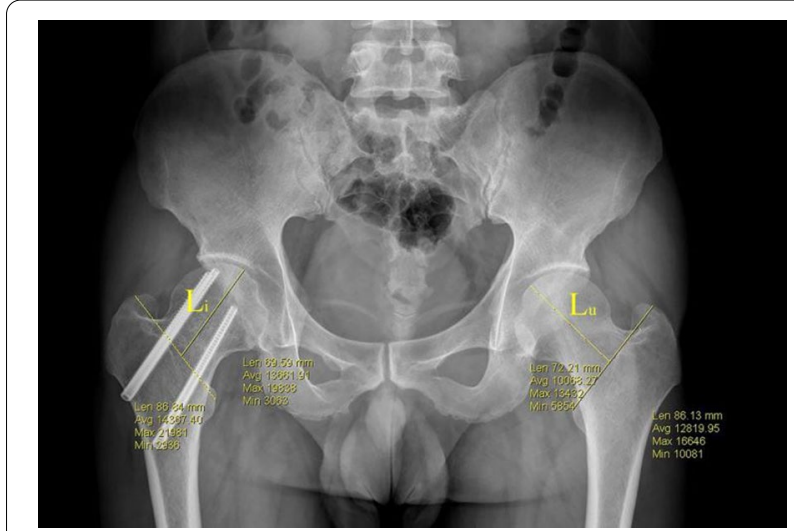

Fig. 2 The measurement of femoral neck shortening. On the anteroposterior radiograph, the line was made through the center of the femoral head in the long axis of the femoral neck on both sides. The distance between the tip of the femoral head and the intertrochanteric line was measured. And the length of femoral neck shortening is the distance on the uninjured side minus the distance on the injured side

\section{Results}

A total of 113 patients treated with FTCCS meeting the inclusion criteria were included in this analysis. There were 67 males and 46 females with an average age of 
$48.4 \pm 13.4$ years (range: $19-70$ years). Among them, 90 $(80 \%)$ patients were younger than 60 years old. The mean duration of follow-up was $27.1 \pm 10.9$ months (range: 12-51 months). In 113 fractures, 68 (60\%) were displaced and $44(39 \%)$ were unstable. Sixty-four $(57 \%)$ fractures were fixed in an inverted triangle configuration and the others were fixed in a triangle configuration. Five (4\%) patients were fixed with four screws.

Among the 113 patients, 38 (33.6\%) cases of complications were confirmed, including 18 (15.9\%) nonunion, 25 (22.1\%) ONFH, and 10 (8.8\%) fixation failure (two or three of these complications occurred concomitantly in 12 cases). The overall reoperation rate was $24.8 \%$ ( 28 cases), including 12 revision to arthroplasty, four revision to internal fixation, two reinsertion of screws and 10 elective removal of implants. With regard to complication and reoperation incidences, there were no significant differences with respect to age, sex, fracture side, fixation configuration, and screw number $(p>0.05)$. Displaced fractures and unstable fractures were potential risk factors for nonunion and reoperation (Table 1).
The rate of nonunion in displaced fractures (24\%) was significantly higher than that in nondisplaced fractures (4\%) $(p=0.007)$. The nonunion rate in unstable fractures (25\%) was higher compared to stable fractures (10\%) $(p=0.035)$. The incidence of fixation failure was also significant higher in unstable fractures $(18-3 \%)(p=0.014)$. And the occurrence of ONFH in displaced fractures was significantly higher than that in nondisplaced fractures $(p=0.022)$.

For FNS, the median length was $2.9 \mathrm{~mm}$ (interquartile range [IQR]: $0.9-6.5 \mathrm{~mm}$, range: $0-17.5 \mathrm{~mm}$ ). In 113 patients, FNS of $>5 \mathrm{~mm}$ occurred in 35 patients, and FNS of $>10 \mathrm{~mm}$ occurred in nine patients. FNS of $\geq 5 \mathrm{~mm}$ was significantly associated with an older age $(48 \%$ of patients older than 60 years vs. $27 \%$ of the other patients, $p=0.050$ ) (Table 2).

\section{Discussion}

The purpose of this study was to evaluate the clinical effectiveness of FTCCS in treating adult patients with FNF. The results showed that the overall rate of

Table 1 Comparison of complication incidence in different groups

\begin{tabular}{|c|c|c|c|c|c|c|c|c|}
\hline & \multicolumn{2}{|c|}{ Nonunion $(n=18,15.9 \%)$} & \multicolumn{2}{|c|}{ ONFH $(n=25,22.1 \%)$} & \multicolumn{2}{|c|}{$\begin{array}{l}\text { Fixation failure }(n=10 \text {, } \\
8.8 \%)\end{array}$} & \multicolumn{2}{|c|}{$\begin{array}{l}\text { Reoperation }(n=28 \text {, } \\
24.8 \%)\end{array}$} \\
\hline & Present & $P$ value & Present & $P$ value & Present & $P$ value & Present & $P$ value \\
\hline \multicolumn{9}{|l|}{ Gender (No, \%) } \\
\hline Male & $14(2)$ & $0.082^{*}$ & $12(18)$ & $0.193^{*}$ & $8(12)$ & $0.290^{*}$ & $16(24)$ & $0.790^{*}$ \\
\hline Female & $4(9)$ & & $13(28)$ & & $2(4)$ & & $12(26)$ & \\
\hline \multicolumn{9}{|l|}{ Fracture side (No, \%) } \\
\hline Left & $10(17)$ & $0.757^{*}$ & $14(24)$ & $0.667^{*}$ & $6(10)$ & $0.853^{*}$ & $15(25)$ & $0.868^{*}$ \\
\hline Right & $8(15)$ & & $11(20)$ & & $4(7)$ & & $13(24)$ & \\
\hline \multicolumn{9}{|c|}{ Fracture displacement (No, \%) } \\
\hline Nondisplaced & $2(4)$ & $0.007^{*}$ & $5(11)$ & $0.022^{*}$ & $1(2)$ & $0.093^{*}$ & $5(11)$ & $0.006^{*}$ \\
\hline Displaced & $16(24)$ & & $20(29)$ & & $9(13)$ & & $23(34)$ & \\
\hline \multicolumn{9}{|c|}{ Fracture stability (No, \%) } \\
\hline Stable & $7(10)$ & $0.035^{*}$ & $13(19)$ & $0.292^{*}$ & $2(3)$ & $0.014^{*}$ & $12(17)$ & $0.023^{*}$ \\
\hline Unstable & $11(25)$ & & $12(27)$ & & $8(18)$ & & $16(36)$ & \\
\hline \multicolumn{9}{|c|}{ Fixation configuration (No, \%) } \\
\hline Triangle & $8(16)$ & $0.920^{*}$ & $12(25)$ & $0.596^{*}$ & $6(12)$ & $0.437^{*}$ & $12(25)$ & $0.950^{*}$ \\
\hline Inverted triangle & $10(16)$ & & $13(20)$ & & $4(6)$ & & $16(25)$ & \\
\hline \multicolumn{9}{|l|}{ Screw number (No, \%) } \\
\hline 3 & $17(16)$ & $0.587^{\#}$ & $24(22)$ & $1.000^{\#}$ & $10(9)$ & $1.000^{\#}$ & $27(25)$ & $1.000^{\#}$ \\
\hline 4 & $1(20)$ & & $1(20)$ & & $0(0)$ & & $1(20)$ & \\
\hline \multicolumn{9}{|l|}{ Age (No, \%) } \\
\hline$\leq 60$ & $14(16)$ & $1.000^{*}$ & $20(22)$ & $0.960^{*}$ & $7(8)$ & $0.702^{*}$ & $22(24)$ & $0.871^{*}$ \\
\hline$>60$ & $4(17)$ & & $5(22)$ & & $3(13)$ & & $6(26)$ & \\
\hline
\end{tabular}

The percentages are based on the number with each variable ONFH: Osteonecrosis of femoral head

${ }^{*} P$ value are based on chi-square test

\# $P$ value are based on Fisher's exact test 
Table 2 Characteristics of femoral neck shorting

\begin{tabular}{|c|c|c|c|c|}
\hline Variable & Total $(n=113)$ & $\mathrm{FNS} \leq 5 \mathrm{~mm}(n=78)$ & FNS $>5 \mathrm{~mm}(n=35)$ & $P$ value \\
\hline Mean age $(\text { years })^{\gamma}$ & $48.4 \pm 13.4$ & $46.6 \pm 14.0$ & $52.5 \pm 11.2$ & $\underline{0.030}$ \\
\hline \multicolumn{5}{|l|}{ Age $(\mathrm{No}, \%)^{*}$} \\
\hline$\leq 60$ years & 90 & $66(73)$ & $24(27)$ & \multirow[t]{2}{*}{$\underline{0.050}$} \\
\hline$>60$ years & 23 & $12(52)$ & $11(48)$ & \\
\hline \multicolumn{5}{|l|}{ Gender $(\mathrm{No}, \%)^{*}$} \\
\hline Male & 67 & $47(70)$ & $20(30)$ & \multirow[t]{2}{*}{0.755} \\
\hline Female & 46 & $31(67)$ & $15(33)$ & \\
\hline \multicolumn{5}{|l|}{ Fracture side $(\mathrm{No}, \%)^{*}$} \\
\hline Left & 59 & $37(63)$ & $22(37)$ & \multirow[t]{2}{*}{0.129} \\
\hline Right & 54 & $41(76)$ & $13(24)$ & \\
\hline \multicolumn{5}{|c|}{ Fracture displacement $(\mathrm{No}, \%)^{*}$} \\
\hline Nondisplaced & 45 & $35(78)$ & $10(22)$ & \multirow[t]{2}{*}{0.102} \\
\hline Displaced & 68 & $43(63)$ & $25(37)$ & \\
\hline \multicolumn{5}{|c|}{ Fracture stability $(\mathrm{No}, \%)^{*}$} \\
\hline Stable & 69 & $48(70)$ & $21(30)$ & \multirow[t]{2}{*}{0.877} \\
\hline Unstable & 44 & $30(68)$ & $14(32)$ & \\
\hline \multicolumn{5}{|c|}{ Fixation configuration $(\mathrm{No}, \%)^{*}$} \\
\hline Triangle & 49 & $33(67)$ & $16(33)$ & \multirow[t]{2}{*}{0.739} \\
\hline Inverted triangle & 64 & $45(70)$ & $19(30)$ & \\
\hline \multicolumn{5}{|c|}{ Screws number (No, \%) ${ }^{\#}$} \\
\hline 3 & 108 & $74(69)$ & $34(31)$ & \multirow[t]{2}{*}{1.000} \\
\hline 4 & 5 & $4(80)$ & $1(20)$ & \\
\hline
\end{tabular}

nonunion, ONFH, and internal fixation failure was 15.9\%, $22.1 \%$, and $8.8 \%$, respectively. The nonunion rate of Pauwels type III in our series was $25 \%$ and the overall median length of FNS was $2.9 \mathrm{~mm}$. We reckon that FTCCS are reasonable to be used in the treatment of FNF.

PTCCS were commonly indicated for the fixation of displaced and nondisplaced femoral neck in patients with good bone stock [4]. It is well-known that this kind of screw relies on the technique of over drilling the near fragment to provide a gliding hole and then under drilling the far fragment to provide a threaded hole. Interfragmentary compression occurs similarly in cases of the screw and the direction of compression are perpendicular to the axis of the fracture. In addition, sliding will happen as long as the angle is $>20^{\circ}$ in relation to its axis [19]. Therefore, one of the advantages is that it enhances fracture healing by compressing the fracture fragments during fixation and eliminating a potential fracture gap by sliding. Clinically, implant sliding can result in FNS and slipping out of the screws, which has been well recognized to be associated with adverse implications and reduced quality of life $[12,20]$.
To date, there were few studies regarding the optimal length of thread of the screw in the treatment of FNF. Dragoni et al. [11] compared the fixation stability of 16-mm threaded, 32-mm threaded, and fully threaded screws. They demonstrated that the increased number of threads in the metaphysis with these screws might provide additional biomechanical strength to the femoral neck. Downey et al. [21] found that the fully threaded screw biomechanically outperformed the partially threaded screw in shear and proved superior in the initial stiffness and failure strength. According to Schaefer et al.s results [12], using a fully threaded positioning screw to replace a posterior partially threaded screw could significantly increase bending stiffness and reduce the displacement of the fracture. Parker et al. [22] observed that nonunion rate was decreased in patients with FNF treated with screws with long thread cannulated cancellous screws. These studies indicate that FTCCS might be a valuable choice for FNF fixation.

FTCCS has been introduced to fix large bones in the upper and lower extremities with the advantage of providing strong compression and holding power for 
fractures to minimize hardware loosening and breakage. In recent years, some alternative ways of FNF fixation using FTCCS have been reported [13, 14, 23]. Weil et al. [23] treated 24 patients with FTCCS and 41 with PTCCS. They revealed that there was no significant difference in nonunion and ONFH rates between the groups. Okcu et al. [14] observed that the use of the same FTCCS as we used in this study increased the nonunion rate $(4 / 22$, $18.2 \%)$ and the time to union. The nonunion rate of our investigation was comparable to theirs ( $15.9 \%$ vs. $18.2 \%)$. Since the configuration of screws was not described in their report, the influence of the configuration of the implants in respect of nonunion could not be evaluated. Meanwhile, they demonstrated that the time to union was significantly longer in patients treated with FTCCS compared with PTCCS, but the hip scores were not significantly different. We did not document these timing data. Logistically, we speculate that a longer time to union may be one disadvantage of this method, but it may not impair the clinical outcomes.

The incidence of nonunion (15.9\%), ONFH (22.1\%), and reoperation $(24.8 \%)$ in the current study was similar to that in recent studies using PTCCS (Table 3) [8, 24-32]. Interestingly, the fixation failure rate in our study was significantly lower. Zhang et al. [13] compared the outcomes of 59 patients with vertical FNF treated with three PTCCS alone and a combination of two FTCCS and one PTCCS. They demonstrated that the incidence of fixation failure and nonunion were significantly lower in the combination group. In the current study, fixation failure was detected in 10 cases with an overall rate of $8.8 \%$, and nonunion in 18 cases with a rate of $15.9 \%$ (Table 1 ). Meanwhile, the fixation failure incidence of nondisplaced group was $2 \%$ which was lower than that of displaced group (13\%), but had no statistically significance based on chi-square test (Table 1). Thus, we believe that fixation with three or four FTCCS is reasonable for the treatment of FNF based on a relatively low incidence of fixation failure.

Classification of FNF has always been done according to the orientation of the fracture line, and relative position of the fracture fragments. The orientation has been described by Pauwels as type I, II, or III [15]. The relative position of fragments has been described by Garden as type I, II, III, and IV [16]. In the present study, nonunion were detected in $4 \%$ of the patients with a nondisplaced fracture (Garden type I, II), and in $24 \%$ with a displaced fracture (Garden type III, IV). It was reported that the nonunion rate of displaced FNF after internal fixation was $33 \%$ in a meta-analysis in which 106 reports were included [33], which is similar to ours. So, our findings indicated that fixation with FTCCS could provide acceptable clinical outcomes in patients with displaced FNF, but more favorable in nondisplaced FNF (Non-union rate, $24 \%$ vs. $4 \%$; ONFH rate, $29 \%$ vs. $9 \%$; reoperation rate, $34 \%$ vs. $11 \%$; Table 1).

It has been well-recognized that FNF with higher shear angles are more unstable, and have a higher tendency of nonunion $[8,33]$. Notably, our nonunion rate of Pauwels type III fracture seems to be higher (25\%) than that in studies about treating FNF with three PTCCS $[8,26,28]$. The reported nonunion rates were $18.9 \%$ [8], 17.4\% [26], and $10.9 \%$ [28]. Hence, it seems that our method did not provide a superiority compared to the traditional techniques in Pauwels type III FNF. Since FTCCS provides additional strength against shear force and reduces the displacement of the FNF compared with PTCCS, the lack of axially dynamic compression after stable fixation may be the reason [13]. But there was still no biomechanical evidence regarding the compression outcome of FTCCS

Table 3 The outcomes of FNF fixed by PTCCS in recent studies

\begin{tabular}{|c|c|c|c|c|c|c|c|}
\hline Author & Year & $\begin{array}{l}\text { Mean } \\
\text { follow-up } \\
\text { (months) }\end{array}$ & No. of patients & Nonunion (\%) & ONFH (\%) & Fixation failure (\%) & Reoperation (\%) \\
\hline Liporace F & 2008 & 24 & 37 & 18.9 & 13.5 & - & - \\
\hline Yang J J & 2013 & $>12$ & 202 & 21.8 & - & - & - \\
\hline Thein $\mathrm{R}$ & 2014 & 16.8 & 47 & 46.8 & 8.5 & - & 34.0 \\
\hline Wang SH & 2015 & 36 & 209 & 8.4 & 11.5 & - & - \\
\hline Siavashi B & 2015 & $>12$ & 28 & - & 10.7 & 17.9 & 28.6 \\
\hline Zhang YL & 2016 & 21.6 & 46 & 10.9 & 17.4 & - & - \\
\hline Chen C & 2017 & 27 & 44 & 4.5 & 9.1 & 27.3 & - \\
\hline Lu Q & 2017 & 38 & 41 & 7.3 & 9.8 & - & 22.0 \\
\hline Alshameeri Z & 2017 & $>12$ & 1279 & 19.5 & 5.6 & - & 19.0 \\
\hline Campenfeldt $P$ & 2017 & 24 & 170 & 15.9 & 14.1 & - & 25.3 \\
\hline Total & & & & $18.3(374 / 2044)$ & $7.7(147 / 1901)$ & $23.0(17 / 74)$ & $20.1(319 / 1564)$ \\
\hline
\end{tabular}


in FNF. In addition, poor reduction quality may also attribute to the result.

FNS has become a noticeable and common implication after FNF internal fixations, leading to functional impairment [10, 34-36]. Felton et al. [34] had indicated that hip function was significantly poorer when FNS was greater than $10 \mathrm{~mm}$, with a similar result reported by Slobogean et al. [37]. Although some scholars demonstrated that FNS did not impair functional outcome after internal fixation of FNF at mid-term follow-up (5.5 years) [38], it has been widely accepted that increasing FNS was associated with worse hip function. In 2008, Zlowodzki et al. [35] reported that in 56 FNF treated with multiple cannulated screws, FNS greater than $10 \mathrm{~mm}$ occurred in $30 \%$ of patients, and this shortened group had significantly lower physical function scores. Recent studies showed when FNF were fixed with a sliding hip screw or multiple cancellous screws, the incidence of severe FNS $(>10 \mathrm{~mm})$ was $12-32 \%$ [34, 37-40], with a median FNS of 3.1$11 \mathrm{~mm}[37-39,41]$. In our study, the median length of FNS was $2.9 \mathrm{~mm}$ and severe FNS greater than $10 \mathrm{~mm}$ was presented only in $8 \%$ patients (nine cases), which seemed to decrease FNS compared with traditional fixation methods. These may be caused by the design features of FTCCS. The fully threaded design provided great holding force and made it hard to allow fractures to slide in the axis of the femoral neck. It was further approved by our finding that the fixation failure incidences either in displaced group or nondisplaced was relatively lower than that of using PTCCS(Tables 1, 3). Furthermore, our study found the median length of FNS in patients $\leq 60$ years old was significantly shorter than that in patients $>60$ years old $(2.6 \mathrm{~mm}$ vs. $4.9 \mathrm{~mm})$. Meanwhile the incidence of the other complications in the $\leq 60$ years old group did not increase. These results demonstrate that FTCCS may be more suitable for relatively young patients. And our previous research has demonstrated that when treating femoral neck nonunion with revision surgery, the success rate was significantly higher when patients had no severe FNS [18]. Consequently, less FNS may offer us the opportunity to achieve better results through revision surgeries, especially for the younger patients.

Some limitations need to be acknowledged in our study. Firstly, our study population was limited to a single center. Thus, we could not generalize to a larger part of China. However, our findings provide evidence for the relative safety and feasibility of the fixation method with FTCCS. Secondly, a control group was lacking, and it is difficult to make a definite value of this method compared to the traditional techniques. Thirdly, the time to surgery of the patientes in our seires was 2-4 days after injury. Thus, the included FNFs were all fresh ones. As we all known, the timing of operation plays a critical role in treatment of FNF. Delayed operation in young patients with FNF may makes it much more difficult to achieve good reduction and fixation because of the aggravated fracture displacement. In addition, the formation of fibrous tissue filling the space between the fracture fragments reduces the possibility to get a satisfied reduction, leads to devastating clinical outcomes. We lack the experiences of treating delayed or old FNF using FTCCS alone. Hence, our results were merely could be adopted in treatment of fresh FNFs. Finally, the bone density was not collected, and accurate measurement may provide different results. Despite these limitations, our findings are clinically significant. The series consisted of a relatively large number of patients and good clinical and radiographic follow-up. All the patients had a mean duration of follow-up of 27 months, and it was adequate to observe development of complications [22].

In conclusion, we found that the screw fixation method with FTCCS provided encouraging clinical results in the treatment of fresh FNF. Unstable fractures and displaced fractures attributed to the higher risk of nonunion, reoperation, and internal fixation failure. These findings demonstrate that FTCCS internal fixation is a proper treatment for FNF.

\section{Abbreviations \\ FNF: Femoral neck fractures; FNS: Femoral neck shortening; FTCCS: Fully threaded cannulated compression screws; ONFH: Osteonecrosis of the femo- ral head; PTCCS: Partially threaded cannulated compression screws. \\ Acknowledgments \\ None. \\ Authors' contributions \\ The study was performed by all the authors. KY, FY, DZ, KF, CJ, DJ, ZW, and XP contributed to the data collection and analysis. The paper was written by KY and FY. Revisions were performed by You-shui Gao and Peng-bo Luo. All the authors check and agree the final version of manuscript. All authors read and approved the final manuscript. \\ Funding \\ None. \\ Availability of data and materials \\ Some or all data used during the study are available from the corresponding author by reasonable request.}

\section{Declarations}

Ethics approval and consent to participate

This study was approved by the Ethics Committee of Shanghai Sixth People's Hospital (Approval Number: 2018-KY-039(K)), and registered in Chinese Clinical Trial Registry (No. ChiCTR1800017200).

Consent for publication

Not applicable.

Competing of interests

The authors report no competing of interest. 
Received: 17 November 2021 Accepted: 9 February 2022

Published online: 20 February 2022

\section{References}

1. Broderick JM, Bruce-Brand R, Stanley E, Mulhall KJ. Osteoporotic hip fractures: the burden of fixation failure. Sci World J. 2013;2013:515197.

2. Gullberg B, Johnell O, Kanis JA. World-wide projections for hip fracture. Osteoporos Int. 1997;7:407-13.

3. Damany DS, Parker MJ, Chojnowski A. Complications after intracapsular hip fractures in young adults. A meta-analysis of 18 published studies involving 564 fractures. Injury. 2005:36:131-41.

4. Panteli M, Rodham P, Giannoudis PV. Biomechanical rationale for implant choices in femoral neck fracture fixation in the non-elderly. Injury. 2015:46:445-52.

5. Florschutz AV, Langford JR, Haidukewych GJ, Koval KJ. Femoral neck fractures: current management. J Orthop Trauma. 2015;29:121-9.

6. Slobogean GP, Sprague SA, Scott T, Bhandari M. Complications following young femoral neck fractures. Injury. 2015:46:484-91.

7. Adravanti P, Pisano F. Subcapital fractures of the femur. Treatment by reduction and fixation and 3 spongy bone screws. Ital J Orthop Traumatol. 1986;12:69-75.

8. Liporace F, Gaines R, Collinge C, Haidukewych GJ. Results of internal fixation of Pauwels type-3 vertical femoral neck fractures. J Bone Joint Surg Am. 2008;90:1654-9.

9. Gurusamy K, Parker MJ, Rowlands TK. The complications of displaced intracapsular fractures of the hip: the effect of screw positioning and angulation on fracture healing. J Bone Joint Surg Br. 2005;87:632-4.

10. Zlowodzki M, Jonsson A, Paulke R, Kregor PJ, Bhandari M. Shortening after femoral neck fracture fixation: is there a solution? Clin Orthop Relat Res. 2007:461:213-8

11. Dragoni M, Heiner AD, Costa S, Gabrielli A, Weinstein SL. Biomechanical study of $16-\mathrm{mm}$ threaded, 32-mm threaded, and fully threaded SCFE screw fixation. J Pediatr Orthop. 2012:32:70-4.

12. Schaefer TK, Spross C, Stoffel KK, Yates PJ. Biomechanical properties of a posterior fully threaded positioning screw for cannulated screw fixation of displaced neck of femur fractures. Injury. 2015;46:2130-3.

13. Zhang B, Liu J, Zhu Y, Zhang W. A new configuration of cannulated screw fixation in the treatment of vertical femoral neck fractures. Int Orthop. 2018;42:1945-55

14. Okcu G, Ozkayin N, Erkan S, Tosyali HK, Aktuglu K. Should full threaded compression screws be used in adult femoral neck fractures? Injury. 2015:46(Suppl 2):S24-8

15. Bartonicek J. Pauwels' classification of femoral neck fractures: correct interpretation of the original. J Orthop Trauma. 2001:15:358-60

16. Garden RS. Low-angle fixation in fractures of the femoral neck. J Bone Joint Surg Br. 1961;43-B:647-63.

17. Ficat RP. Idiopathic bone necrosis of the femoral head. Early diagnosis and treatment. J Bone Joint Surg Br. 1985;67:3-9.

18. Yin J, Zhu H, Gao Y, Zhang C. Vascularized fibular grafting in treatment of femoral neck nonunion: a prognostic study based on long-term outcomes. J Bone Joint Surg Am. 2019:101:1294-300.

19. Johner R, Joerger K, Cordey J, Perren SM. Rigidity of pure lag-screw fixation as a function of screw inclination in an in vitro spiral osteotomy. Clin Orthop Relat Res. 1983;178:74-9.

20. Weil YA, Khoury A, Zuaiter I, Safran O, Liebergall M, Mosheiff R. Femora neck shortening and varus collapse after navigated fixation of intracapsular femoral neck fractures. J Orthop Trauma. 2012;26:19-23.

21. Downey MW, Kosmopoulos V, Carpenter BB. Fully threaded versus partially threaded screws: determining shear in cancellous bone fixation. J Foot Ankle Surg. 2015;54:1021-4.

22. Parker MJ, Ali SM. Short versus long thread cannulated cancellous screws for intracapsular hip fractures: a randomised trial of 432 patients. Injury. 2010;41:382-4.

23. Weil YA, Qawasmi F, Liebergall M, Mosheiff R, Khoury A. Use of fully threaded cannulated screws decreases femoral neck shortening after fixation of femoral neck fractures. Arch Orthop Trauma Surg. 2018:138:661-7.

24. Yang JJ, Lin LC, Chao KH, Chuang SY, Wu CC, Yeh TT, et al. Risk factors for nonunion in patients with intracapsular femoral neck fractures treated with three cannulated screws placed in either a triangle or an inverted triangle configuration. J Bone Joint Surg Am. 2013;95:61-9.

25. Thein R, Herman A, Kedem P, Chechik A, Shazar N. Osteosynthesis of unstable intracapsular femoral neck fracture by dynamic locking plate or screw fixation: early results. J Orthop Trauma. 2014;28:70-6.

26. Wang SH, Yang JJ, Shen HC, Lin LC, Lee MS, Pan RY. Using a modified Pauwels method to predict the outcome of femoral neck fracture in relatively young patients. Injury. 2015;46:1969-74.

27. Siavashi B, Aalirezaei A, Moosavi M, Golbakhsh MR, Savadkoohi D, Zehtab MJ. A comparative study between multiple cannulated screws and dynamic hip screw for fixation of femoral neck fracture in adults. Int Orthop. 2015;39:2069-71.

28. Zhang YL, Chen S, Ai ZS, Gao YS, Mei J, Zhang CQ. Osteonecrosis of the femoral head, nonunion and potential risk factors in Pauwels grade-3 femoral neck fractures: a retrospective cohort study. Medicine (Baltimore). 2016;95:e3706.

29. Chen C, Yu L, Tang X, Liu MZ, Sun LZ, Liu C, et al. Dynamic hip system blade versus cannulated compression screw for the treatment of femoral neck fractures: a retrospective study. Acta Orthop Traumatol Turc. 2017:51:381-7.

30. Lu Q, Tang G, Zhao X, Guo S, Cai B, Li Q. Hemiarthroplasty versus internal fixation in super-aged patients with undisplaced femoral neck fractures: a 5-year follow-up of randomized controlled trial. Arch Orthop Trauma Surg. 2017;137:27-35.

31. Alshameeri Z, Elbashir M, Parker MJ. The outcome of intracapsular hip fracture fixation using the Targon Femoral Neck (TFN) locking plate system or cannulated cancellous screws: a comparative study involving 2004 patients. Injury. 2017:48:2555-62.

32. Campenfeldt P, Hedstrom M, Ekstrom W, Al-Ani AN. Good functional outcome but not regained health related quality of life in the majority of 20-69 years old patients with femoral neck fracture treated with internal fixation: a prospective 2-year follow-up study of 182 patients. Injury. 2017:48:2744-53.

33. Lu-Yao GL, Keller RB, Littenberg B, Wennberg JE. Outcomes after displaced fractures of the femoral neck. A meta-analysis of one hundred and six published reports. J Bone Joint Surg Am. 1994;76:15-25.

34. Felton J, Slobogean GP, Jackson SS, Della Rocca GJ, Liew S, Haverlag R et al. Femoral neck shortening after hip fracture fixation is associated with inferior hip function: results from the FAITH trial. J Orthop Trauma. 2019:33:487-96.

35. Zlowodzki M, Ayeni O, Petrisor BA, Bhandari M. Femoral neck shortening after fracture fixation with multiple cancellous screws: incidence and effect on function. J Trauma. 2008;64:163-9.

36. Zlowodzki M, Brink O, Switzer J, Wingerter S, Woodall J Jr, Petrisor BA, et al. The effect of shortening and varus collapse of the femoral neck on function after fixation of intracapsular fracture of the hip: a multi-centre cohort study. J Bone Joint Surg Br. 2008;90:1487-94.

37. Slobogean GP, Stockton DJ, Zeng BF, Wang D, Ma B, Pollak AN. Femoral neck shortening in adult patients under the age of 55 years is associated with worse functional outcomes: analysis of the prospective multi-center study of hip fracture outcomes in China (SHOC). Injury. 2017:48:1837-42.

38. Haider T, Schnabel J, Hochpochler J, Wozasek GE. Femoral shortening does not impair functional outcome after internal fixation of femoral neck fractures in non-geriatric patients. Arch Orthop Trauma Surg. 2018;138:1511-7.

39. Stockton DJ, Lefaivre KA, Deakin DE, Osterhoff G, Yamada A, Broekhuyse $H M$, et al. Incidence, magnitude, and predictors of shortening in young femoral neck fractures. J Orthop Trauma. 2015;29:e293-8.

40. Liu Y, Ai ZS, Shao J, Yang T. Femoral neck shortening after internal fixation. Acta Orthop Traumatol Turc. 2013:47:400-4.

41. Zielinski SM, Keijsers NL, Praet SF, Heetveld MJ, Bhandari M, Wilssens JP, et al. Femoral neck shortening after internal fixation of a femoral neck fracture. Orthopedics. 2013;36:e849-58.

\section{Publisher's Note}

Springer Nature remains neutral with regard to jurisdictional claims in published maps and institutional affiliations. 